\section{Detection of antibiotic residues among raw beef in Erbil City (Iraq) and impact of tempera- ture on antibiotic remains}

\author{
Dhary Alewy Al-mashhadany \\ Department of Pathological Analysis, \\ Knowledge University College of \\ Science, Erbil, Kurdistan Region, Iraq
}

\begin{abstract}
The presence of antibiotic residues in beef is considered a serious threat to public health. This study aimed to detect antibiotic residues in raw beef and the impact of low and high temperature treatments on residues persistence. A total of 250 sampleswere collected from retail markets in Erbil city (Iraq) and analyzed microbiologically in plates pre-inoculated with Bacillus subtilis. The overall occurrence of antibiotics residues was $(10.8 \%)$. The highest rate was detected in January (16.7\%). Cooking for thirty minutes completely deactivate antibiotic residues against the challenged bacterium. In conclusion, the presence of antibiotic residues in beef samples in Erbil city was high and their persistence is markedly reduced by cooking.
\end{abstract}

\section{Introduction}

Antibiotics are secondary metabolites from certain bacterial and fungal species with harmful properties against other bacterial species. These compounds play pivotal roles in agricultural, veterinary, and clinical settings (Schwarz et al., 2001). Furthermore, they are widely used in foodproducing animals for therapeutic, prophylactic, and metaphylactic purposes (Baynes et al., 2016; Sarker et al., 2018) Antibiotic residues term refers to molecules that remain in meat and organs of slaughtered animals that have been given antibiotics earlier without adherence to withdrawal period of the antibiotic (Darko et al., 2017; Aidara-kane et al., 2018). Globally, antibiotics have been extensively used in the field of animal farming in due to their availability and low price. Moreover, antibiotics have been employed to enhance the growth and productivity (Tang et al., 2017; Kirchhelle, 2018).

Most humans are vigilant toward consumption of meat from farm industry that massively uses antibiotics in their production process. This cautious attitude resulted from the fact that antibiotic residues or their derivatives remain in meat. It is worth mentioning that various antibiotics require different time periods to be eliminated from the body. This time period is identified as withdrawal period (WP) for the particular antibiotic. The length of WP depends on the dosage form, antibiotic type, and method of administration. The withdrawal time ranges from only few hours to numerous days or weeks, so this period must be observed in ante mortem inspection of cattle (Almashhadany et al., 2018; Okocha et al., 2018).Lack of knowledge between animal producers about withdrawal periods of antibiotics along with improper use of antibiotics are the main reasons that contribute to the problem. The presence of antibiotic residues above the Maximum Residue Limits (MRLs) in food produced from these animals is considered globally, by various public health authorities, as illegal practice (Jayalakshmi et al., 2017; Regea, 2018). The hazardous threats of such residues including direct toxicity, drug allergy, hypersensitive reaction and development of antibiotic resistant bacteria that have been known as a global health challenge in the $21^{\text {st }}$ century. Moreover, antibiotic residues may also influence starter cultures in food industry leading to economic losses (Beyene, 2016; Prajwal et al., 2017; Manyiloh et al., 2018). The presence of antibiotic residues in different types of meat has been widely investigated in several countries (Alla et al., 2011; Babapour et al., 2012; Mangsi et al., 2014; Mgonja et al., 2017; Ramatla et al., 2017; Ashraf et al., 2018).

Bacterial infections in cattle seem to be often associated with rainy season. In Saudi Arabia, the highest incidence rate of mastitis in cattle was found during the cold season (summer) in a three-year study (Shathele, 2009). Moreover, cattle brucellosis in Uganda was found to peak during seasons of heavy rains (Mwebe et al., 2011). On the other hand, the highest rate of diarrheal infections in calves of cattle in northern India was reported after the onset of rains during spring and summer seasons (Malik et al., 2012). On the contrary, a study from Uganda found that dry season is associated with increase in bacterial infections in cattle but not in poultry. This observation was explained by the movement of cattle in search for food (Byaruhanga et al., 2017). Additionally, a recent study from Bangladesh has found that the highest prevalence of various bacterial diseases in bovine occurs in the rainy summer season (Mohammed et al., 2017).

In recent decades, there has been a significant increase of antibiotic residues in food of animal origin, including red meat, therefore this study aimed to investigate the
Correspondence: Dhary Alewy Al-mashhadany, Department of Pathological Analysis, Knowledge University College of Science, PO Box 074016 Daratoo st. 123, Kirkuk Road, Erbil, Kurdistan Region, Iraq.

E-mail: alewi1987@gmail.com

Key words: Antibiotic Residues, Raw Beef, Erbil City, Temperature, Kurdistan Region, Iraq.

Conflict of interest: The author declares no conflict of interest.

Funding: Knowledge University, Kurdistan, Iraq

Received for publication: 23 October 2018.

Revision received: 29 January 2019

Accepted for publication: 11 February 2019

This work is licensed under a Creative Commons Attribution-NonCommercial 4.0 International License (CC BY-NC 4.0).

CCopyright D.A. Al-mashhadany., 2019 Licensee PAGEPress, Italy

Italian Journal of Food Safety 2019; 8:7897 doi:10.4081/ijfs.2019.7897

occurrence of antibiotic residues in beef in Erbil city and to determine the correlation between occurrence of antibiotic residues and months during the period of research, as well as investigate the effects of low and high temperature on persistence of these residues.

\section{Materials and Methods}

\section{Determination of carcasses age}

Cattle carcasses age was determined according to previously published criteria (Tatum, 2011). Briefly, carcass's age is assigned either as young carcass (around 24 months) or adult carcass (more than 24 months) by examining the ossification of the tips or buttons of the thoracic vertebrae, the size and shape of the ribs, in addition to the color and texture of the flesh.

\section{Sample collection}

A total of 250 thigh beef samples from carcasses of young and adult cattle (125 of each) were randomly collected from slaughter houses and malls in different retail markets in Erbil city, during the period from January to June 2018. The collected samples were placed in separate plastic bags and transported to Pathological Analysis Department, College of Science, Knowledge University, under chilling condition. In the laboratory. 


\section{Preparation of the spore suspension}

Spores suspension of Bacillus subtilis was prepared at desired concentration according to standard methods (ALRubeae, 2000). Briefly, Heavy inoculums of $B$. subtilis were introduced to the surface of a Nutrient agar plate (HiMedia, India). The plates were incubated at $30^{\circ} \mathrm{C}$ for 10 days to induce sporulation. After the incubation period, colonies were harvested into $10 \mathrm{~mL}$ of sterile normal saline and heated at $70^{\circ} \mathrm{C}$ for 10 minutes to kill the vegetative cells. The heated suspension was centrifuged at $3000 \mathrm{rpm}$ for 10 minutes. The clear supernatant was discarded. Another $10 \mathrm{~mL}$ of sterile saline were added to wash off debris of vegetative cells. The mixture was concentrated at the same speed and duration. The process was repeated twice to obtain a pure suspension of endospores. Suspension turbidity was adjusted to match $0.5 \mathrm{McF}$ arland standard solutions $\left(\approx 1.5 \times 10^{8} \mathrm{CFU} / \mathrm{mL}\right)$.

\section{Preparation of test plates}

Muller-Hinton agar was prepared as recommended by the manufacturing company (HiMedia, India). After cooling to approximately $45^{\circ} \mathrm{C}$, inoculum of $0.1 \mathrm{~mL}$ of spore suspension was introduced to each $100 \mathrm{~mL}$ of the agar before solidification. The molten agar was poured into petridishes and allowed to solidify at room temperature. Plates were used at the same day of preparation or held at refrigerator and used within one week.

\section{Detection of antibiotic residues in samples}

A previously published technique (Almashhadany, 2009) was adapted for the detection of antibiotic residues in beef samples. A disc-shaped meat sample of $2 \mathrm{~mm}$ in thickness and $8 \mathrm{~mm}$ in diameter was prepared and placed on the surface of MullerHinton agar inoculated by the sensitive test organism (Bacillus subtilus). The plates were incubated aerobically at $37^{\circ} \mathrm{C}$ for 24 hrs. Formation of transparent zone equal or more than to $2 \mathrm{~mm}$ was considered as a positive result. However, a zone of 1 to $2 \mathrm{~mm}$ was considered as suspicious one, and a zone less than $1 \mathrm{~mm}$ was considered as a negative result. The zone size around each positive sample was measured using Vernier caliper. Since no zone appeared in control samples, zones diameters of samples were recorded for evaluation.

\section{Impact of food preservative methods} on positive samples

The effects of preservation methods on residues persistence were evaluated as follows:

Cooling: Beef samples which showed positive results in the direct method were kept in the refrigeration at $\left(4^{\circ} \mathrm{C}\right)$. After 3 days, samples were examined for the persistence of antibiotic residues by the direct method.

Freezing: Beef samples which showed positive results in the direct method were kept in a freezing compartment at $\left(-18^{\circ} \mathrm{C}\right)$. After 4 weeks, antibiotic residues presence was evaluated by the direct method.

Cooking (Boiling): About 20-25 grams of each residue-positive sample were placed into a sieve and immersed in $100 \mathrm{~mL}$ of water bath preheated to $100^{\circ} \mathrm{C}$ for $30 \mathrm{minu}-$ tes. Samples then removed and allowed to cool before re-evaluation for antibiotic residues.

Statistical analysis: All statistical calculations were done using version 15 of SPSS software. Chi-Square test was employed to assess the different responses between beef samples to preservative methods. A level was set to 0.05 .

Table 1. Occurrence of antibiotic residues in raw beef samples.

\begin{tabular}{lccc} 
Age of beef & No. samples & No. positive (\%) & No. negative (\%) \\
Young & 125 & $12(9.6)$ & $113(90.4)$ \\
Adult & 125 & $15(12.0)$ & $110(88.0)$ \\
\hline Total & 250 & $27(10.8)$ & $223(89.2)$ \\
\hline
\end{tabular}

\section{Results}

\section{Occurrence of antibiotic residues in beef samples}

Out of 250 raw beef samples, 27 $(10.8 \%)$ werepositive for the presence of antibiotic residues (Inhibition zones diameter ranged from $2 \mathrm{~mm}$ to $8 \mathrm{~mm}$ ). Of note, $9 \%(12 / 125)$ of samples from young carcasses were positive, while $12 \%(15 / 125)$ of adult carcasses samples were harboring antibiotic residues (Table 1). Based on statistical inference, at any given month, it is estimated that $7.4-14.1 \%$ (95\% confidence interval) of raw beef meat in Erbil market is contaminated by antibiotic residues.

\section{Changes in rate of antibiotic residues during study period}

The change in occurrence rate of antibiotic residues was monitored through study period. The highest rate of residues detection was observed in late summer; January (17\%) and February (14.6), while the lowest rate was found in June $(5 \%)$. Table 2 summarizes the detection rates in temporal scale.

\section{Effects of preservative methods on persistence of antibiotic residues}

The effectiveness of cooling $\left(4^{\circ} \mathrm{C} / 3\right.$ days) on the occurrence of antibiotic residues in positive raw beef samples was low. Indeed, third of residues-positive beef samof the residues after cooling (Table 3). However, such difference between young and adult beef samples is not significant.

On the other hand, freezing at $-18^{\circ} \mathrm{C}$ for ples of young carcasses showed clearance

Table 2. Relationship between months and occurrence of antibiotic residues in beef samples.

\begin{tabular}{|c|c|c|c|c|c|c|}
\hline \multirow[t]{2}{*}{ Month } & \multicolumn{2}{|c|}{ Young beef } & \multicolumn{2}{|c|}{ Adult beef } & \multirow[t]{2}{*}{ Total examined } & \multirow[t]{2}{*}{ Total positive (\%) } \\
\hline & No. exam & No. Post & №. exam & No. post & & \\
\hline January & 20 & 3 & 22 & 4 & 42 & $7(16.7)$ \\
\hline February & 21 & 3 & 20 & 3 & 41 & $6(14.6)$ \\
\hline March & 20 & 2 & 20 & 1 & 40 & $3(7.5)$ \\
\hline April & 23 & 1 & 21 & 4 & 44 & $5(11.4)$ \\
\hline May & 21 & 2 & 22 & 2 & 43 & $4(9.3)$ \\
\hline June & 20 & 1 & 20 & 1 & 40 & $2(5.0)$ \\
\hline Total & 125 & 12 & 125 & 15 & 250 & $27(10.8)$ \\
\hline
\end{tabular}


four weeks was less effective than cooling on the clearance of antibiotic residues in raw beef samples. Likewise, residues-positivesamples of beef from young carcasses showed more response than adult derived samples to antibiotic clearance by freezing (Table 4). Despite the fact that beef ofyoung carcasses responds more than beef of adults to clearance by cooling or freezing methods, this difference is not statistically significant. On the contrary, heat processing $\left(100^{\circ} \mathrm{C}\right.$ for 30 minutes) showed complete $(100 \%)$ deactivation of antibiotic residues against challenged bacteria (data not shown).

\section{Discussion}

Over the past decades, beef industry has become popular and increased dramatically worldwide. Antibiotics are critical components of cattle farming practice and beef industry but their uses regimen should adhere strictly to the legislated regulations (Correa et al., 2018; Shang et al., 2018). The World Health Organization (WHO) confirmed that antibiotic resistance is an international issue and countermeasures should be taken to mitigate the progressive spread of resistant bacteria species and the practices leading to resistance evolution (Okocha et al., 2018). Antibiotic residues in animal-derived food may contribute to the development of resistant bacteria. Consequently, Codex Alimentarius Commission (CAC) recommends that Food of animal origin treated with veterinary medicines/drugs must not contain any residue (CAC, 2017).

In the present study, the occurrence rate of antibiotic residues in total beef samples was $10.8 \%$. The highest rate $(12 \%)$ was found in beef adult carcasses, while the lowest $(9.6 \%)$ rate was documented in young carcasses (Table 1). These findings are consistent with an Egyptian study that found the prevalence of Oxytetracycline (OTC) residues in $10 \%$ of examined imported beef meat samples (Elbagory et al., 2016). Additionally, another Egyptian report states that $16 \%$ of the examined raw meat was contaminated by antibiotics (ElWehedy et al., 2018). In contrast, only 3\% occurrence rate was reported in muscles beef samples analyzed in Sudan (Alla et al., 2011). Moreover, In Vietnam, the occurrence rate in beef samples was found to be 7.4\% (Yamaguchi et al., 2015).

On the other hand, higher rates have been reported previously. In Iran, antibiotic residues were detected in $22.8 \%$ of screened beef (Babapour et al., 2012). Strikingly, a Pakistani study (Mangsi et al., 2014) report- ed a high presence rate $(38.33 \%)$. Most recently, an Ethiopian study estimated that $71 \%$ to $82 \%$ of fresh beef in a northwest market harbor antibiotic residue (Agmas and Adugna, 2018). Such discrepancies could be attributed to failure to adhere to pre-slaughter withdrawal period or the improper massive use of antibiotics by farmers (Khatun et al., 2018).

In beef, the average values of acidity and fat contents are higher than the average of poultry meats, while protein contents were high in poultry than in beef (Pereira and Vicente, 2013). Additionally, beef contains narrow muscle fibers while poultry meat contains broad fibers. However, results showed that difference in fat composition and content between beef and poultry has no effect in protecting the antibiotic residues against the thermal deactivation of

cooking. In this work, the correlation between months and incidence of antibiotic residues in beef meat duringthe period of study in Erbil city was monitored. Table 2 shows that the highest detection of antibiotic residues from overall samples was found in January $7 / 42(16.7 \%)$, approximately close to this rate in February 6/41 (14.6\%). It is obvious that there is an association (Figure 1) between increase in residues occurrence rate and other unknown environmental parameter(s) (temperature, humidity... etc.), which somehow may have affected the cattle and required antibiotic intervention by farmers.

In terms of various antibiotic residues rates and seasons, a Sudanese study (Alla et al., 2011) noticed that the largest rate $(24 \%)$ was documented in summer, which is in good agreement with this study.

Table 3. Effect of cooling $\left(4^{\circ} \mathrm{C} / 3\right.$ days) on antibiotic residues persistence in beef samples.

\begin{tabular}{lcccc} 
Types of samples & $\begin{array}{c}\text { No. of positive } \\
\text { before cooling }\end{array}$ & $\begin{array}{c}\text { No. of affected } \\
\text { sample after } \\
\text { cooling (\%) }\end{array}$ & Chi-Square & $\chi^{2}{ }_{t}$ \\
Young & 12 & $4(33.3)$ & 1.54 & 3.84 \\
Adult & 15 & $2(13.3)$ & & \\
\hline Total & 27 & $6(22.2)$ & & \\
\hline
\end{tabular}

Table 4. Impact of Freezing $\left(-18^{\circ} \mathrm{C} / 4\right.$ weeks) on antibiotic residues in raw beef samples.

\begin{tabular}{lcccc} 
Types of samples & $\begin{array}{c}\text { No. of positive } \\
\text { before freezing }\end{array}$ & $\begin{array}{c}\text { No. of affected } \\
\text { sample after } \\
\text { freezing (\%) }\end{array}$ & Chi-Square & $\chi^{2}{ }_{t}$ \\
Young & 12 & $2(16.7)$ & 0.67 & 3.84 \\
Adult & 15 & $1(6.7)$ & & \\
\hline Total & 27 & $3(11.1)$ & & \\
\hline
\end{tabular}

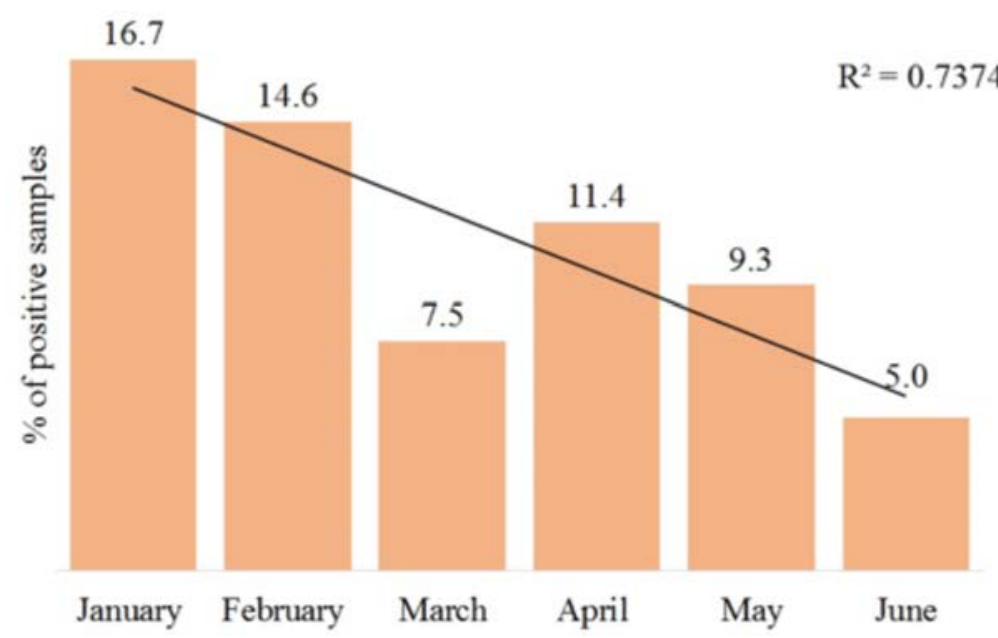

Figure 1. Correlation between study months and percentage of positive samples. 
Furthermore, the finding also agrees with an Iranian study (Aalipour et al., 2013) in Iran showed that the highest contamination rate of milk with antibiotic residues occurred in summer (February, 45\%). Wetness of natural pasture in winter may lead to occurrence of diseases that require intervention practice including antibiotics. In fact, it has been reported that winter season is associated with increased rate of antibiotic residues in poultry meat samples examined in Kurdistan region (Al-mashhadany, 2009).

The cooling and freezing methods (Tables 3 and 4) produced roughly similar effects on reduction of antibiotic residues in beef. There is a shortage of information on the effect of cooling and freezing in determining the fate of antibiotic residues in beef. However, all heat processed samples (27 samples; $100^{\circ} \mathrm{C}$ for 30 minutes) showed total reduction in activity of antibiotic residues against test bacteria (Data not shown). These findings are consistent with an Egyptian study who reported that antibiotics disappeared in the cooked meat samples (El-Wehedy et al., 2018). This may be attributed to the destructive effects of heat on antibiotics.

Various cooking methods (boiling, frying, and grilling) were compared based on the reduction of oxytetracycline and ampicillin residues in meat samples of chicken muscle (Elbagory et al., 2016). Nonetheless, the study reported grilling and frying to be superior to boiling in reduction percentage of both antibiotics. These findings are further supported by a recent study that found a reduction of OTC with boiling up to $91 \%$ in 30 minutes and barbecued meat up to $88 \%$ in 20 minutes (Mgonja et al., 2017).Such variations are most likely resulted from different degrees of applied heat, the type of antibiotics, or even the meat per se.

Due to differences in the overall immunity between young and adult cattle, different infections have been found likely to be age-related (Busato et al., 1999; Nielsen and Ersbøll, 2006; Brooks-Pollock et al., 2013). Consequently, different antibiotics are administered at different doses. However, no significant difference in response to thermal treatments has been found between young and adult beef samples in this study.

\section{Conclusions}

Antibiotic residues in red meat, especially beef, are one of a significant public health challenge for Iraqi Kurdistan. According to the results obtained in this study, the occurrence rate of antibiotic resi- due in beef samples collected from Erbil city was higher than recommended. Cooling and freezing slightly reduce the antibiotic residues in beef but boiling for half an hour successfully reduces residues efficacy. However, the in vivo products of heatdegraded antibiotic are obscure. Their potential harms and interactions worth studying with special emphasis on the toxicological potentials.

\section{References}

Aalipour F, Mirlohi M, Jalali M, 2013. Prevalence of antibiotic residues in commercial milk and its variation by season and thermal processing methods. Int J Env Health Eng 2:41.

Agmas B, Adugna M, 2018. Antimicrobial residue occurrence and its public health risk of beef meat in Debre Tabor and Bahir Dar, Northwest Ethiopia. Vet World 11:902.

Aidara-Kane A, Angulo FJ, Conly JM, Minato Y, Silbergeld EK, McEwen SA, Collignon PJ, 2018. World Health Organization (WHO) guidelines on use of medically important antimicrobials in food-producing animals. Antimicrob Resist Infect Control 7:7.

Al-mashhadany DA, 2009. Detection of Antibiotic Residues in Red Meat and the Effect of Heat Treatment on Them. Thamar Univ J Studies Res B:17-28.

Al-rubeae AHQ, 2000. Study of Residues of Antibiotics in Sheep and Goats Meat: Unpublished M.Sc. Thesis, Baghdad, Iraq. Department of Public Health College of Veterinary Medicine, Univ of Baghdad.

Alla MB, Mohamed TE, Abdelgadir AE, 2011. Detection of Antibiotics Residues in Beef in Ghnawa Slauterhouse, Khartoum State, Sudan J Vet Med Anim Product 10;2.

Al-Mashhadany DA, Nahla AA, Zaki AM, Mohammad VS, 2018. Detection of Antibiotic Residues among Poultry Meat in Erbil City and Impact of Thermal Processing on Remnants. Res J Life Sci Bioinform Pharm Chem Sci 3:237-47.

Ashraf N, Rashid A, Naz U, Ashraf MM, Khaliq S, Khan IA, Nazir A, Mohsin NU, Sarwar A, Asif R, Malik A, 2018. Detection of Antibiotics Residues in protein containing diets (Meat and Eggs) of human through different methods. J Univ Med Dent Coll 9:1-11.

Babapour A, Azami L, Fartashmehr J, 2012. Overview of antibiotic residues in beef and mutton in Ardebil, North West of Iran. World Appl Sci J 19:1417-22.
Baynes RE, Dedonder K, Kissell L, Mzyk D, Marmulak T, Smith G, Tell L, Gehring R, Davis J, Riviere JE, 2016. Health concerns and management of select veterinary drug residues. Food Chem Toxicol 29:112-22.

Beyene T, 2016. Veterinary drug residues in food-animal products: its risk factors and potential effects on public health $\mathrm{J}$ Vet Sci Technol 7:285.

Brooks-Pollock E, Conlan AJ, Mitchell AP, Blackwell R, McKinley TJ, Wood, JL, 2013. Age-dependent patterns of bovine tuberculosis in cattle. Vet Res 44:97.

Busato A, Hofer D, Lentze T, Gaillard C, Burnens A, 1999. Prevalence and infection risks of zoonotic enteropathogenic bacteria in Swiss cow-calf farms. Vet Microbiol 69:251-63.

Byaruhanga J, Tayebwa DS, Eneku W, Afayoa M, Mutebi F, Ndyanabo S, Kakooza S, Okwee-Acai J, Tweyongyere R, Wampande EM, Vudriko P, 2017. Retrospective study on cattle and poultry diseases in Uganda. Int J Vet Sci Med 5:168-74.

Codex Alimentarius Commission (CAC), 2017. Maximum Residue Limits (MRLs) and Risk Management Recommendations (RMRs) For Residues of Veterinary Drugs in Foods. CAC/MRL 2-2017. Updated as at the 40th Session of the Codex Alimentarius Commission.

Correa DA, Castillo PM, Martelo RJ, 2018. Beef's Antibiotics Residues Determination from Arjona and Magangué Municipalities in Bolívar, Colombia. Contemp Eng Sci 11:1695702.

Darko G, Borquaye LS, Acheampong A, Oppong K, 2017. Veterinary antibiotics in dairy products from Kumasi, Ghana. Cogent Chem 1;3:1343636.

Elbagory AM, Yasin NA, Algazar EA, 2016. Effect of Various Cooking Methods on Some Antibacterial Residues in Imported and Local Frozen Dressed Broilers and their Giblets in Egypt. Nutr Food Technol 2.

El-Wehedy SE, Darwish WS, Tharwat AE, Hafez AE, 2018. Estimation and Health Risk Assessment of Toxic Metals and Antibiotic Residues in Meats Served at Hospitals in Egypt. J Vet Sci Technol $9: 2$.

Jayalakshmi K, Paramasivam M, Sasikala M, Tamilam TV, Sumithra A, 2017. Review on antibiotic residues in animal products and its impact on environments and human health. J Entomol Zool Studies 5:1446-51.

Khatun R, Howlader AJ, Ahmed S, Islam N, Alam K, Haider S, Mahmud MS, Hasan 
MA, 2018. Validation of the Declared Withdrawal Periods of Antibiotics. Uni J Public Health 6:14-22.

Kirchhelle C, 2018. Pharming animals: a global history of antibiotics in food production (1935-2017). Palgrave Comms vol 4, Article number: 96.

Malik S, Verma AK, Kumar A, Gupta MK, Sharma SD, 2012. Incidence of calf diarrhea in cattle and buffalo calves in Uttar Pradesh, India. Asian J Anim Vet Adv 7:1049-54.

Mangsi AS, Khaskheli M, Soomro AH, 2014. Antibiotic residues detection in raw beef meat sold for human consumption in sindh, Pakistan. Inter $\mathrm{J}$ Res Appl Nat Soc Sci 2:15-20.

Manyi-Loh C, Mamphweli S, Meyer E, Okoh A, 2018. Antibiotic use in agriculture and its consequential resistance in environmental sources: Potential public health implications. Molecules 23:795.

Mgonja F, Mosha R, Mabiki F, Choongo K, 2017. Effect of heat treatment on oxytetracycline residues in beef. Am J Res Comm 5:1-13.

Mohammed MO, Rahman MS, Hoque MF, Rumi NA, Afrah OH, 2017. Study on prevalence of bovine diseases at sadar upazila in dinajpur district of Bangladesh. Asian J Med Biol Res 3:446-53.

Mwebe R, Nakavuma J, Moriyón I, 2011. Brucellosis seroprevalence in livestock in Uganda from 1998 to 2008: a retro- spective study. Trop Anim Health Prod 43:603-8.

Nielsen SS, Ersbøll AK, 2006. Age at occurrence of Mycobacterium avium subspecies paratuberculosis in naturally infected dairy cows. J Dairy Sci 89:4557-66.

Okocha RC, Olatoye IO, Adedeji OB, 2018. Food safety impacts of antimicrobial use and their residues in aquaculture. Public Health Rev 39:21.

Pereira PMDCC, Vicente AFDRB, 2013. Meat nutritional composition and nutritive role in the human diet. Meat Sci 93:586-92.

Prajwal S, Vasudevan VN, Sathu T, Irshad A, Nayankumar SR, Pame K, 2017. Antibiotic residues in food animals: Causes and health effects. Pharma Innov J 6:1-4.

Ramatla T, Ngoma L, Adetunji M, Mwanza M, 2017. Evaluation of Antibiotic Residues in Raw Meat Using Different Analytical Methods. Antibiot 6:34.

Regea G, 2018. Review on Antibiotics Resistance and its Economic Impacts. J Pharmacol Clin Res 5:555675.

Sarker YA, Hasan MM, Paul TK, Rashid SZ, Alam MN, Sikder MH, 2018. Screening of antibiotic residues in chicken meat in Bangladesh by thin layer chromatography. J Adv Vet Animal Res 5:140-5.

Schwarz S, Kehrenberg C, Walsh TR, 2001. Use of antimicrobial agents in veterina- ry medicine and food animal production. Int J Antimicrob Agents 17:431-7.

Shang N, Chaplot S, Wu J, 2018. Food proteins for health and nutrition. In: Proteins in Food Processing 2nd ed. Yada RY, ed. Woodhead Publishing Series in Food Science, Technology and Nutrition, Duxford, UK. p. 301-336.

Shathele MS, 2009. Weather effect on bacterial mastitis in dairy cows. Int J Dairy Sci 4:57-66.

Tang KL, Caffrey NP, Nóbrega DB, Cork SC, Ronksley PE, Barkema HW, Polachek AJ, Ganshorn H, Sharma N, Kellner JD, Ghali WA, 2017. Restricting the use of antibiotics in food-producing animals and its associations with antibiotic resistance in foodproducing animals and human beings: a systematic review and meta-analysis. Lancet Planet Health 1:e316-27.

Tatum JD, 2011. Animal age, physiological maturity, and associated effects on beef tenderness. Cattlemen's Beef Board and National Cattlemen's Beef Association. Colorado State University.

Yamaguchi T, Okihashi M, Harada K, Konishi Y, Uchida K, Do MH, Bui HD, Nguyen TD, Nguyen PD, Chau VV, Dao KT, 2015. Antibiotic residue monitoring results for pork, chicken, and beef samples in Vietnam in 2012-2013. J Ag Food Chem 63:5141-5. 